\title{
Editorial Special issue: Culham Thesis Prize winners
}

\author{
C J $\mathrm{Ham}^{\dagger}$ \\ CCFE, Culham Science Centre, Abingdon, Oxfordshire OX14 3DB, United Kingdom
}

It is my great pleasure to edit this special issue of JPP devoted to winners of the Culham Thesis Prize.

The Culham Thesis Prize is awarded annually to the nominee who has displayed an excellence in the execution of the scientific method as witnessed by the award of Doctor of Philosophy in Plasma Science from a UK or Irish university. The thesis content should exhibit significant new work and originality, clearly driven by the nominee, be well explained and demonstrate a good understanding of the subject. The prize is awarded at the Institute of Physics Plasma Physics Group Spring Conference and the prize winner gives an invited talk about their thesis work. The prize is sponsored by Culham Centre for Fusion Energy.

The Culham Thesis Prize recognizes early achievement and it is right to celebrate this more widely than just within the conference hall. This issue gives an opportunity to all those who have won the Culham Thesis Prize to provide an article either on their prize winning work or on a topic of current interest. Future winners of the prize will be invited to submit an article on their research. A picture and short biography of the prize winners will appear with their articles. I hope that this will motivate current students and allow them to see the route others have taken to achieve research success.

I would like to thank all of the judges of the Culham Thesis Prize for their efforts over the years. The nominations are generally of a very high quality and can be very diverse in their subjects. The judges have been extremely diligent in trying to identify the most worthy winners.

The Culham Thesis Prize was first awarded in 2002 and has been awarded to nominees investigating laser-plasma interactions, magnetic confinement fusion and low temperature plasmas. The prize displays the strength in depth and breadth of the UK and Irish Plasma Physics community. The results of this work have implications for many applications from medical imaging and treatment through to electricity generation. The prize winners have often gone on to research positions in the rest of the world and to positions of influence in the Plasma Physics community in the UK.

I hope you enjoy reading these articles and trust that they serve as an inspiration to current students and supervisors.

My congratulations to all the Culham Thesis Prize winners!

Current organizer of the Culham Thesis Prize 


\section{Winners of the Culham Thesis Prize 2002-2014}

2002 Dr Eugene Clark, Imperial College London

For ground breaking research on proton and ion acceleration in ultra intense laserplasma interactions.

2003 Dr Roderick Kennedy, University of Oxford

For innovative research on the application of probe theory to dust particles immersed in plasma.

2004 Dr Andrea Ciardi, Imperial College London

For laboratory investigation and modelling of hypersonic jets in wire array Z-pinch experiments.

2005 Dr Barney Walton, Imperial College London

For novel experimental investigations of beat-wave acceleration as intense electromagnetic fields interact with material in a plasma state.

2006 Dr Stuart P D Mangles, Imperial College London

For measurements of relativistic electrons from intense laser-plasma interactions.

2007 Dr Phil Nilson, Imperial College London

For measurements of the dynamics of laser and soft X-ray heated targets by XUV and optical probing.

2008 Dr Louise Willingale, Imperial College London

For significant experimental and numerical work on the acceleration of ions to high energies by laser-plasma interaction.

2009 Dr Ben Dudson, University of Oxford

For his thesis 'Edge turbulence in the Mega-Amp Spherical Tokamak'.

2010 Dr Ian Chapman, Imperial College London

For his thesis 'Modelling the stability of the $\mathrm{n}=1$ internal kink mode in tokamak plasmas'.

2011 Dr Stefan Kneip, Imperial College London

For his thesis 'Laser-plasma accelerator and wiggler'.

2012 Dr S M Vinko, University of Oxford

For his thesis 'Studying dense plasmas using intense UV and X-ray free-electron laser radiation'.

2013 Dr Charlotte Palmer, Imperial College, London

For her thesis 'Approaching the radiation pressure regime of proton acceleration with high intensity lasers'.

2014 Dr Guy Burdiak, Imperial College London

For his thesis 'An investigation of cylindrical liner Z-pinches as drivers for converging strong shock experiments'. 